\title{
Intramural gastric abscess following laparoscopic paraesophageal hernia repair
}

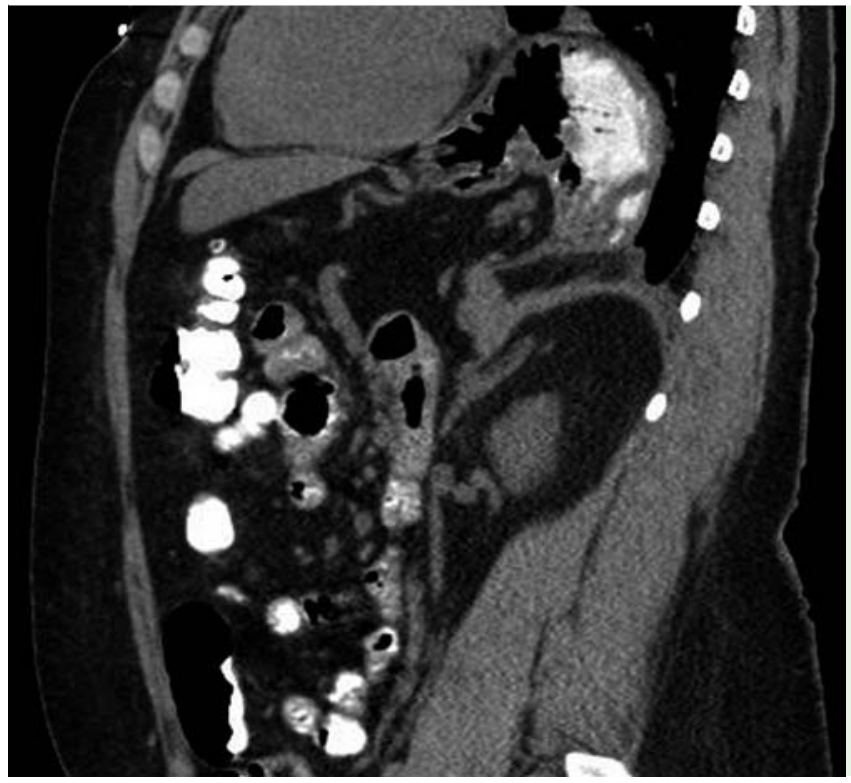

Fig. 1 Sagittal reconstruction of a preoperative computed tomography $(\mathrm{CT})$ scan showing a large crural defect and intrathoracic stomach.

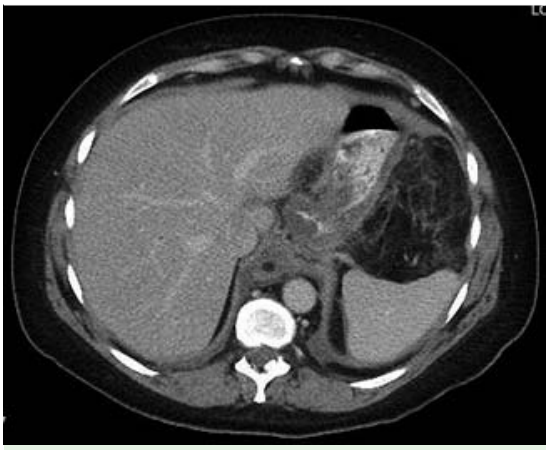

Fig. 2 Computed tomography (CT) scan on re-admission 24 days after initial discharge showing upper abdominal fluid collections, a thickened gastric wall, and postoperative inflammatory changes.
A 46-year-old woman underwent laparoscopic paraesophageal hernia repair for an intrathoracic stomach ( $\bullet$ Fig. 1). After the surgery, she was discharged from the hospital in good condition, but 24 days later, she re-presented with progressive nausea, vomiting, and persistent globus sensation. Physical examination revealed mild tenderness in the left upper quadrant. Laboratory findings included a leukocytosis, mild electrolyte abnormalities, and a low serum albumin level.

She was admitted to the hospital and given parenteral nutrition. Abdominal computed tomography (CT) was performed, which revealed multiple small fluid collections in the upper abdomen, fat stranding near the proximal stomach, and a prominent proximal gastric wall ( $\bullet$ Fig.2). Endoscopy was performed and a draining fundal abscess was discovered and aspirated ( Fig.3). Antibiotic therapy was initiated. Subsequently, the patient's symp- toms and leukocytosis resolved. She was discharged from the hospital in improved condition.

Laparoscopic paraesophageal hernia repair is safe, associated with low recurrence rates, and provides excellent longterm symptomatic relief. However, complications occur in up to $10 \%$ of patients [1]. Esophageal or gastric perforation, gastric volvulus, aortic or cardiac injury, mediastinal abscess, anatomic recurrence, and erosion of the mesh cruroplasty into the esophagus or stomach have all been reported [1-5].

We present here the first reported case of an intramural gastric abscess after laparoscopic paraesophageal hernia repair. Spontaneous gastric abscesses have been described previously. Considered rare and idiopathic, the diagnosis was in the past made at laparotomy and surgical therapy was advocated; however, this paradigm is evolving. Diagnosis is now possible by CT [6,7], and successful endoscopic ultrasound (EUS) evaluation and drainage have been described [7-9].

The signs and symptoms of this disease process are insidious. In this case, the findings even on advanced imaging studies were insufficient to make the diagnosis. We suggest that early endoscopy be considered when new or recurrent symptoms develop after laparoscopic paraesophageal hernia repair. Endoscopic drainage may then be therapeutic, obviating the need for reoperation.

Endoscopy_UCTN_Code_CPL_1AM_2AF

Competing interests: None

\section{Will Cole, Stanley Zagorski}

Department of General Surgery, Tripler Army Medical Center, Honolulu, Hawaii, USA 


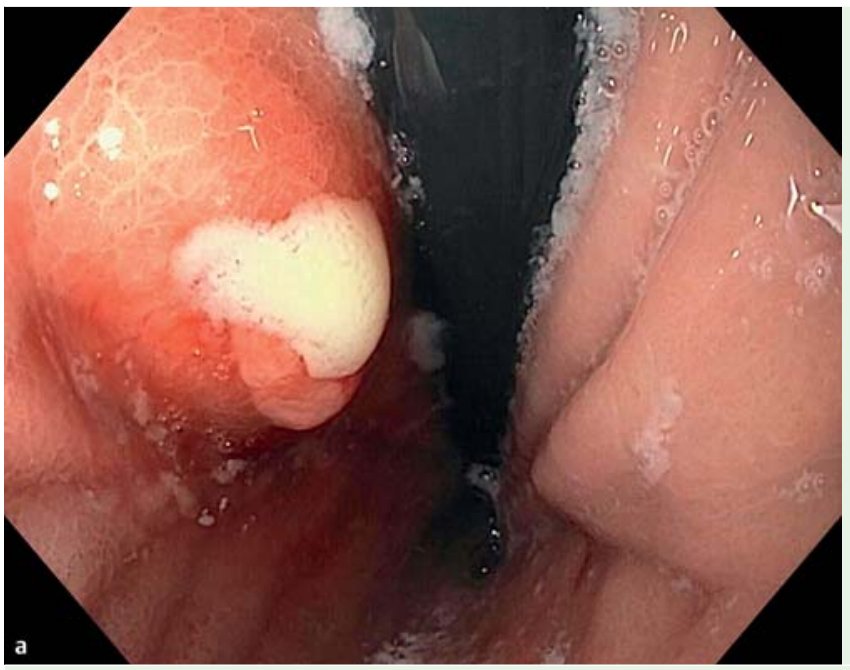

Fig. 3 Endoscopic views showing: a a draining abscess in the fundus of the stomach; $\mathbf{b}$ the abscess being aspirated endoscopically; $\mathbf{c}$ the area of lesion after aspiration.
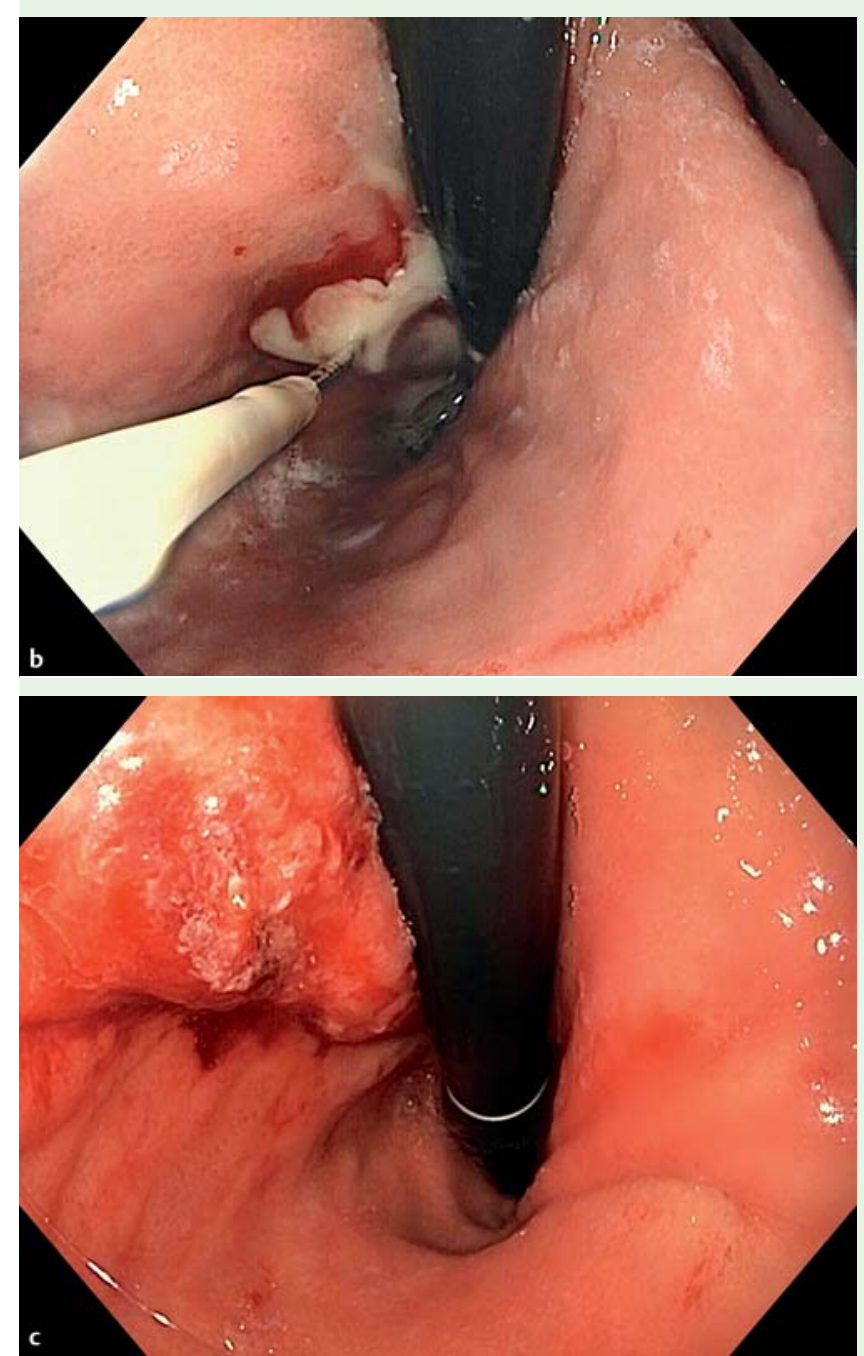

\section{References}

1 Mattar SG, Bowers SP, Galloway KD et al. Long-term outcome of laparoscopic repair of paraesophageal hernia. Surg Endosc 2002; 16: $745-749$

2 Trus TL, Bax T, Richardson WS et al. Complications of laparoscopic paraesophageal hernia repair. J Gastrointest Surg 1997; 1: 221 228

3 Zugel N, Lang RA, Kox M et al. Severe complication of laparoscopic mesh hiatoplasty for paraesophageal hernia. Surg Endosc 2009; 23: $2563-2567$

4 Makarewicz W, Jaworski L, Bobwicz M et al. Paraesophageal hernia repair followed by cardiac tamponade caused by ProTacks. Ann Thorac Surg 2012; 94: e87-e89

5 Sato K, Filipi CJ, Shiino $Y$ et al. An unusual case of gastric volvulus after laparoscopic paraesophageal hernia repair. Surg Endosc 2001; 15: 757-760

6 Asrani A, Novelline R, Abujudeh $\mathrm{H}$ et al. Intramural gastric abscess - preoperative diagnosis with CT. Emerg Radiol 2007; 14: 253-256

7 Kang BC, Kim KW, Lee SW et al. Gastric wall abscess: imaging, diagnosis and endoscopic treatment. J Comput Assist Tomo 2008; 22: 673-675

8 Kiil C, Rosenberg J. Gastric intramural abscess successfully drained during gastroscopy. Gastrointest Endosc 2001; 53: 231 233

9 Chahal P, Levy MJ. Potential utility of EUS in the diagnosis and management of intramural gastric abscess. Gastroenterol Hepatol 2008; 4: 644-645

\section{Bibliography}

DoI http://dx.doi.org/

10.1055/s-0034-1365439

Endoscopy 2015; 47: E227-E228

(c) Georg Thieme Verlag KG

Stuttgart · New York

ISSN 0013-726X

\section{Corresponding author}

\section{Will Cole, MD}

Department of Surgery

1 Jarrett White Rd

Honolulu

Hawaii, 96859

USA

williamcharlescole@gmail.com 